Military Technical College Cairo, Egypt

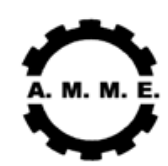

$12^{\text {th }}$ International Conference on Applied Mechanics and Mechanical Engineering (AMME)

\title{
IMPROVEMENT OF TRACTOR SEMITRAILER STABILITY DURING SEVERE MANEUVER AT HIGH SPEED
}

\author{
Elhemly ${ }^{*}$ M. A., Zeyada ${ }^{* *}$ Y. and Fayed ${ }^{* * *}$ M. A.
}

\section{ABSTRACT}

This paper presents a new control strategy called "Semitrailer Differential Braking Technique (SDBT)" to improve the dynamic stability of 2 axle tractor combined with 3 axle semitrailer equipped with a standard antilock braking system (ABS) during evasive maneuver at high speed. A Matlab Simulink model constructed to study the dynamic stability under different driving conditions; brake sequence, driver input, steering response, road type, and loading condition. The new concept based on monitoring of the yaw rate difference between the tractor and semitrailer, and applying differential braking on the semitrailer at certain articulation rate threshold. The results show improving of the handling performance of the combination against rollover and jackknifing during evasive maneuver at high speed.

\section{KEYWORDS}

Jackknifing; handling performance; stability control; semitrailers; articulation rate; heavy vehicles; fifth wheel; semitrailer differential braking technique; yaw rate;

* PhD. Application, Faculty of Engineering, Cairo University

** Associated professor, Dpt. of Mech. Design and Production, Cairo University

*** Associated professor, Mechanical Engineering Branch, Military Technical Collage 


\section{NOMENCLATURE}

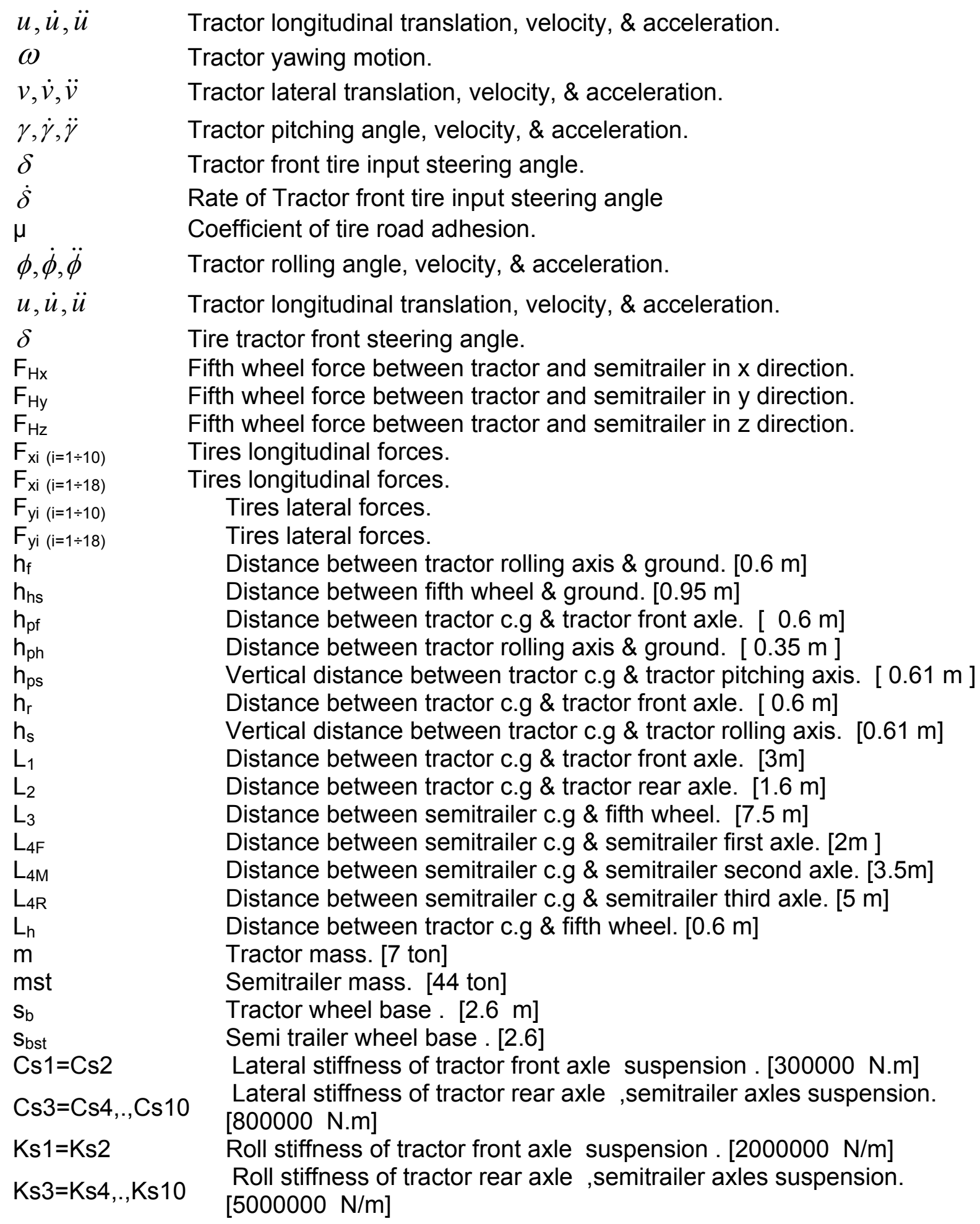

$u, \dot{u}, \ddot{u}$

$\omega$

$v, \dot{v}, \ddot{v}$

$\gamma, \dot{\gamma}, \ddot{\gamma}$

$\delta$

$\dot{\delta}$

$\mu$

$\phi, \dot{\phi}, \ddot{\phi}$

$u, \dot{u}, \ddot{u}$

$\delta$

$\mathrm{F}_{\mathrm{Hx}}$

$\mathrm{F}_{\mathrm{Hy}}$

$\mathrm{F}_{\mathrm{Hz}}$

$F_{x i(i=1 \div 10)}$

$F_{x i}(i=1 \div 18)$

$F_{y i}(i=1 \div 10)$

$F_{y i(i=1 \div 18)}$

$h_{f}$

$\mathrm{h}_{\mathrm{hs}}$

$h_{\text {pf }}$

$\mathrm{h}_{\mathrm{ph}}$

$h_{p s}$

$h_{r}$

$\mathrm{h}_{\mathrm{s}}$

$\mathrm{L}_{1}$

$L_{2}$

$\mathrm{L}_{3}$

$\mathrm{L}_{4 \mathrm{~F}}$

$\mathrm{L}_{4 \mathrm{M}}$

$L_{4 R}$

$L_{h}$

$\mathrm{m}$

mst

$\mathrm{s}_{\mathrm{b}}$

$S_{b s t}$

$\mathrm{Cs} 1=\mathrm{Cs} 2$

Cs3 $=$ Cs $4, ., C s 10$

$\mathrm{Ks} 1=\mathrm{Ks} 2$

$\mathrm{Ks} 3=\mathrm{Ks} 4, ., \mathrm{Ks} 10$

Tractor longitudinal translation, velocity, \& acceleration.

Tractor yawing motion.

Tractor lateral translation, velocity, \& acceleration.

Tractor pitching angle, velocity, \& acceleration.

Tractor front tire input steering angle.

Rate of Tractor front tire input steering angle

Coefficient of tire road adhesion.

Tractor rolling angle, velocity, \& acceleration.

Tractor longitudinal translation, velocity, \& acceleration.

Tire tractor front steering angle.

Fifth wheel force between tractor and semitrailer in $\mathrm{x}$ direction.

Fifth wheel force between tractor and semitrailer in y direction.

Fifth wheel force between tractor and semitrailer in $z$ direction.

Tires longitudinal forces.

Tires longitudinal forces.

Tires lateral forces.

Tires lateral forces.

Distance between tractor rolling axis \& ground. [0.6 m]

Distance between fifth wheel \& ground. [0.95 m]

Distance between tractor c.g \& tractor front axle. [ $0.6 \mathrm{~m}$ ]

Distance between tractor rolling axis \& ground. [ $0.35 \mathrm{~m}$ ]

Vertical distance between tractor c.g \& tractor pitching axis. [ $0.61 \mathrm{~m}$ ]

Distance between tractor c.g \& tractor front axle. [ $0.6 \mathrm{~m}$ ]

Vertical distance between tractor c.g \& tractor rolling axis. [0.61 m]

Distance between tractor c.g \& tractor front axle. [3m]

Distance between tractor c.g \& tractor rear axle. [1.6 m]

Distance between semitrailer c.g \& fifth wheel. [7.5 m]

Distance between semitrailer c.g \& semitrailer first axle. [2m ]

Distance between semitrailer c.g \& semitrailer second axle. [3.5m]

Distance between semitrailer c.g \& semitrailer third axle. [5 m]

Distance between tractor C.g \& fifth wheel. [0.6 m]

Tractor mass. [7 ton]

Semitrailer mass. [44 ton]

Tractor wheel base . [2.6 m]

Semi trailer wheel base . [2.6]

Lateral stiffness of tractor front axle suspension . [300000 N.m]

Lateral stiffness of tractor rear axle ,semitrailer axles suspension.

[800000 N.m]

Roll stiffness of tractor front axle suspension . [2000000 N/m]

Roll stiffness of tractor rear axle ,semitrailer axles suspension. [5000000 N/m] 


\section{INTRODUCTION}

One of the main objectives of the control of vehicle dynamics is to improve the handling performance, or maneuverability, in order to obtain safer and more joyful driving. A range of systems are commercially available today, such as antilock braking, active stability control, yaw control, and traction control. Many new systems are under consideration, in parallel with efforts to integrate and coordinate the currently existing. In this process, models are necessary tools to analyze and design the control strategies and to evaluate the dynamic performance of the full-scale systems. In this paper a 10 DOF tractor-semitrailer dynamic handling model (longitudinal, lateral, yaw, roll, \&pitch for both bodies) of a tractor-semitrailer combination has been adapted from Tetsuya Kaneko [5]. Another 4DOF (longitudinal, lateral, vertical, \& rotational) for the 18 tire has been constructed. A simulink program has been developed to simulate tractor semitrailer motion including tractor, semitrailer, axle and suspension, tire, and brake model. A predefined maneuver scenario is used to simulate driver behavior and road conditions, initial velocity, which are the inputs to the program. Validation of the simulation program is done through comparing results with previous work made by Tetsuya Kaneko [5]. This program is used to investigate the dynamic performance of a 2 axle tractor combined with 3 axle semitrailer during evasive high speed lane change maneuver. Identification of the jackknifing threshold through simulation of the vehicle (2 axel tractor combined with 3 axle semitrailers) to move straight forward at different initial speeds $\left(u_{0}=70,80,90\right.$, and $\left.110 \mathrm{~km} / \mathrm{h}\right)$ for $2 \mathrm{sec}$ and the driver faces an obstacle so he had to make an evasive lane change maneuver with front steering angle pattern as shown in Figure 1. The driver response was taken into consideration $30 \mathrm{deg} / \mathrm{Sec}$, on dry road. The only way is to control the tire forces during turning by applying brake force on appropriate side tires [14].

In this paper a new control concept called Semitrailer Differential Braking Technique (SDBT), has been developed by the authors to eliminate jackknifing. The new control strategy analyzed in this paper does not depend on the driver's behavior because it prevents the occurrence of critical situation before the driver takes action or even before taking in appropriate action resulting in improving of the dynamic stability of the combination against rollover and jackknifing during evasive maneuver at high speed.

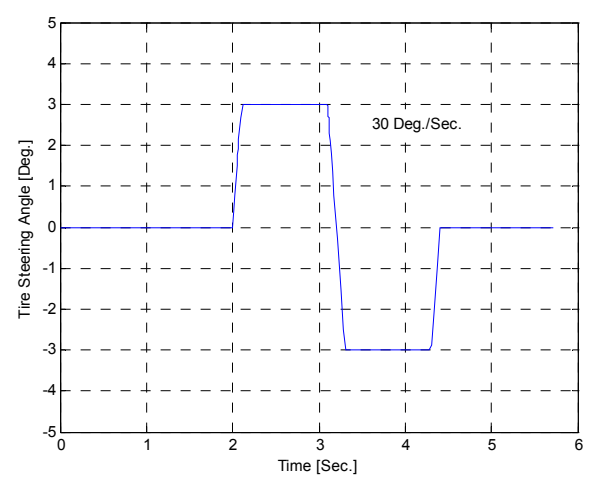

Fig. 1. Steering input at tractor front axle tires. 


\section{MATHEMATICAL MODEL}

A 10 DOF tractor-semitrailer dynamic handling model (longitudinal, lateral, yaw, roll, \&pitch for both bodies) of a tractor-semitrailer combination has been adapted with previous work made by Tetsuya Kaneko [5].

A 4DOF (longitudinal, lateral, vertical, \& rotational) for the 18 tires. The equations of motion are derived from the fundamental equations of motion. The tractor motion was described by equation (1) to equation (5), the semitrailer motion was described by equation (6), (7), (8), (9)and (10). The tractor semitrailer interaction(fifth wheel)was described by equation (11), (12), (13) and (14). On real suspension systems the load transfer has great influence, to capture this phenomenon correctly it is necessary to use a model with sprung masses, that are connected to the unsprung body parts by the suspension system as shown in figure 2 .

The analyzed vehicle is a Mercedes-Benz tractor semitrailer, with the tractor denominated LS1935 with 4x2 traction system. With the following main specifications, according to information given by the tractor and semitrailer manufacturers [25]: - Model of the tractor: LS1935; Traction system: 4x2;

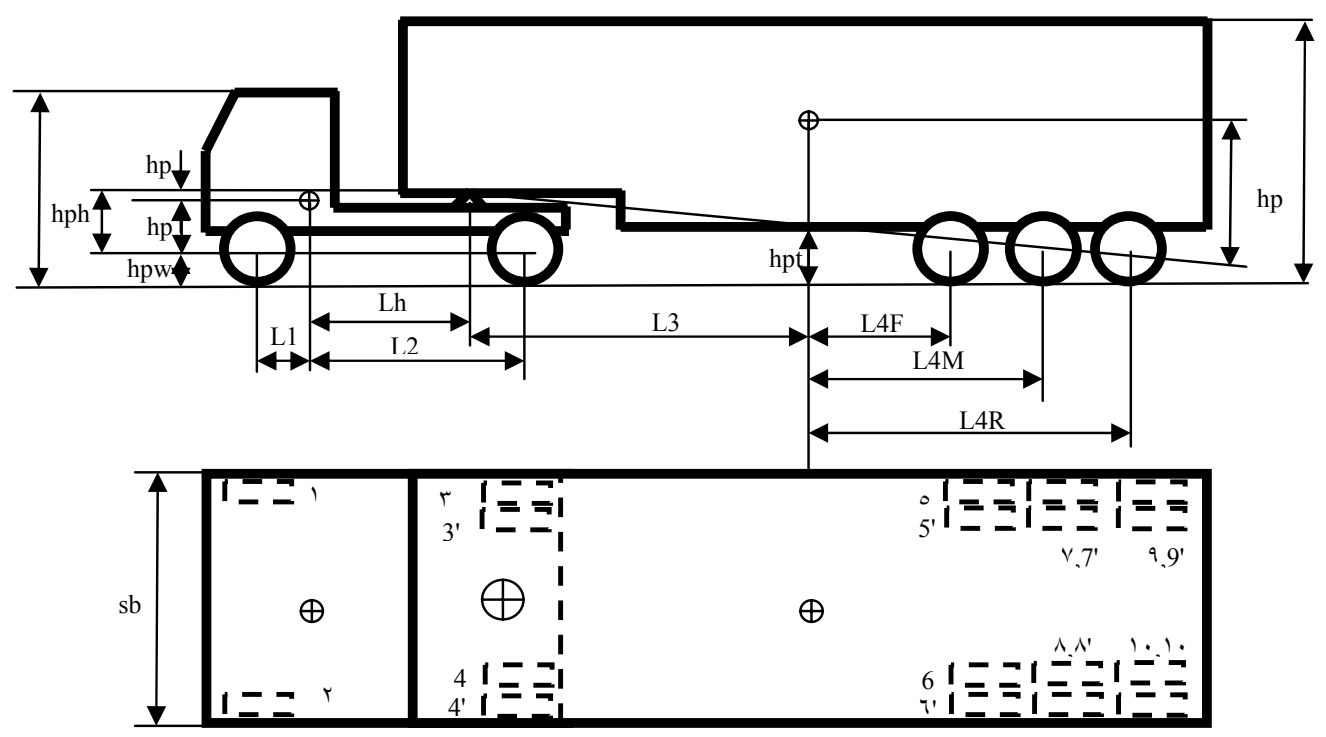

Fig. 2. A 2-axle tractor combined with 3-axle semitrailer

Tractor motion

$$
\begin{aligned}
& m\left(\dot{u}-\omega v+h_{p s} \ddot{\gamma}\right)=\left(F_{y 1}+F_{y 2}\right) \sin \delta-\left(F_{x 1}+F_{x 2}\right) \cos \delta-F_{x 3}-F_{x 4}+F_{H x} \\
& m\left(\dot{v}+\omega u-h_{s} \ddot{\phi}\right)=\left(F_{x 1}+F_{x 2}\right) \sin \delta-\left(F_{y 1}+F_{y 2}\right) \cos \delta-F_{y 3}+F_{y 4}+F_{H y} \\
& I_{z} \dot{\omega}=\left[-\left(F_{x 1}+F_{x 2}\right) \sin \delta-\left(F_{y 1}+F_{y 2}\right) \cos \delta\right] L_{1}+\left(F_{y 3}+F_{y 4}\right) L_{2} \\
& -\left[\left(F_{y 2}-F_{y 1}\right) \sin \delta+\left(F_{x 1}-F_{x 2}\right) \cos \delta\right] s_{b} / 2-\left(F_{x 3}-F_{x 4}\right) s_{b} / 2-L_{h} F_{H y}
\end{aligned}
$$




$$
\begin{aligned}
& I_{x} \ddot{\phi}-m\left(\dot{v}+\omega v-h_{s} \ddot{\phi}\right) h_{s}=\left(F_{z 1}-F_{z 2}+F_{z 3}-F_{z 4}\right) s_{b} / 2 \\
& +\left[\left(F_{x 1}-F_{x 2}\right) \sin \delta+\left(F_{y 1}+F_{y 2}\right) \cos \delta\right] h_{f}+\left(F_{y 3}+F_{y 4}\right) L_{2}+\left(F_{y 3}+F_{y 4}\right) h_{r} \\
& +m g h_{s} \sin \phi-F_{H y} h_{h s} \\
& I_{y} \ddot{\gamma}-m\left(\dot{u}+\omega v+h_{p s} \ddot{\gamma}\right) h_{p s}=\left[\left(F_{x 1}+F_{x 2}\right) \cos \delta-\left(F_{y 1}+F_{y 2}\right) \sin \delta\right] h_{p f} \\
& +\left(F_{x 3}+F_{x 4}\right) h_{p r}-\left(F_{z 1}+F_{z 2}\right) L_{1}+\left(F_{z 3}+F_{z 4}\right) L_{2}+m g h_{p s} \gamma+F_{H x} h_{p h}-F_{H z} L_{h}
\end{aligned}
$$

Semi trailer motion

$$
\begin{aligned}
& m_{s t}\left(\dot{u}_{s t}-\omega_{s t} v_{s t}+h_{p s t} \ddot{\gamma}_{s t}\right)=-F_{x 5}-F_{x 6}-F_{x 7}-F_{x 8}-F_{x 9}-F_{x 10} \\
& -F_{H x} \cos \psi+F_{H y} \sin \psi \\
& m_{s t}\left(\dot{v}_{s t}+\omega_{s t} u_{s t}-h_{s t} \ddot{\phi}_{s t}\right)=-F_{y 5}-F_{y 6}-F_{y 7}-F_{y 8}-F_{y 9}-F_{y 10} \\
& -F_{H x} \sin \psi+F_{H y} \cos \psi \\
& I_{z s t} \dot{\omega}_{s t}=\left(F_{y 5}+F_{y 6}+F_{y 7}+F_{y 8}+F_{y 9}+F_{y 10}\right) L_{4} \\
& +\left(F_{x 5}-F_{x 6}+F_{x 7}-F_{x 8}+F_{x 9}-F_{x 10}\right) s_{b} / 2-\left(F_{H y} \cos \psi+F_{H x} \sin \psi\right) L_{3} \\
& I_{x s t} \ddot{\phi}_{s t}-m_{s t}\left(\dot{v}_{s t}+\omega_{s t} u_{s t}-h_{s t} \ddot{\phi}_{s t}\right) h_{s t}=\left(F_{z 5}-F_{z 6}+F_{z 7}-F_{z 8}+F_{z 9}-F_{z 10}\right) s_{b} / 2 \\
& \left(F_{y 5}+F_{y 6}+F_{y 7}+F_{y 8}+F_{y 9}+F_{y 10}\right) h_{t}+m_{s t} g h_{s t} \sin \phi_{s t} \\
& I_{y s t} \ddot{\gamma}_{s t}+m_{s t}\left(\dot{u}_{s t}-\omega_{s t} v_{s t}+h_{p s t} \ddot{\gamma}_{s t}\right) h_{p s t}=\left[\left(F_{x 5}+F_{x 6}+F_{x 7}+F_{x 8}+F_{x 9}+F_{x 10}\right) h_{p s t}\right. \\
& +\left(F_{z 5}+F_{z 6}+F_{z 7}+F_{z 8}+F_{z 9}+F_{z 10}\right) L_{4}+m_{s t} g h_{p s t} \gamma_{s t} \\
& +\left(-F_{H x} \cos \psi+F_{H y} \sin \psi\right) h_{p h}-F_{H z}
\end{aligned}
$$

\subsection{Fifth wheel modeling}

Relationship between vehicle speeds and relative angles are governed by the following equations:

$$
\begin{aligned}
& \left(u+h_{p h} \dot{\gamma}\right) \cos \psi-\left(v-h_{h s} \dot{\phi}-L_{h} \omega\right) \sin \psi=u_{s t}+h_{p h t} \dot{\gamma}_{s t} \\
& \left(u+h_{p h} \dot{\gamma}\right) \sin \psi+\left(v-h_{h s} \dot{\phi}-L_{h} \omega\right) \cos \psi=v_{s t}+L_{3} \omega_{s t} \\
& L_{h} \dot{\gamma}=-L_{3} \dot{\gamma}_{s t}+L_{3} \omega_{s t} \\
& \left(u+h_{p h} \dot{\gamma}\right) \sin \psi+\left(v-h_{h s} \dot{\phi}-L_{h} \omega\right) \cos \psi=v_{s t}+L_{3} \omega_{s t}
\end{aligned}
$$

\subsection{Tire modeling}

A ready made Matlab file called STI developed by System Technology Corporation was adopted to calculate the tire forces. Tire normal load, slip ratio, \& slip angle are the inputs to the model, then through a series of algebraic and empirical equations based on experiments used to produce longitudinal and lateral forces, according to the following scheme (figure 3). 
Tire normal load Longitudinal slip ratio Slip angle

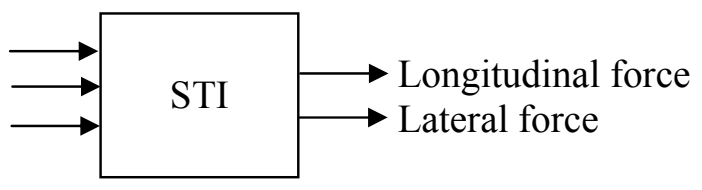

Fig.3. Scheme for the STI tire model

\subsection{Simulation program}

A Matlab/Simulink model was constructed to simulate tractor semitrailer performance. The model(shown in figure 4) consists of two sprung inertial bodies, connected through the hitch coupling which introduces the constraints on the relative motion of the tractor and the semitrailer. The unsprung bodies (axles) are assumed to be mass less. Suspension characteristics at each wheel are included. The initial velocity, maneuver scenario, braking sequence, and road type, are the inputs to the model. Figure 2 shows the main blocks of the simulation program. Different analysis and investigations for the handling performance are done through simulation outputs.

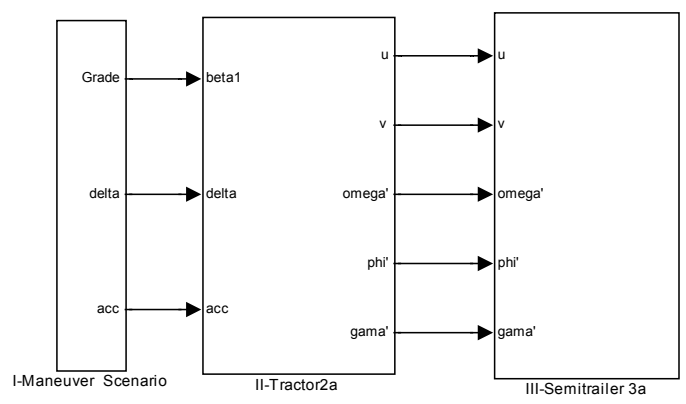

Fig.4. Main blocks of the simulation program

\subsection{Tractor model}

To tractor motion simulate by a predefined initial velocity, and using the inputs: road type, steering angle, longitudinal and lateral forces. The model outputs are: tractor longitudinal, lateral, yawing, rolling, pitching velocity as shown in figure 5.
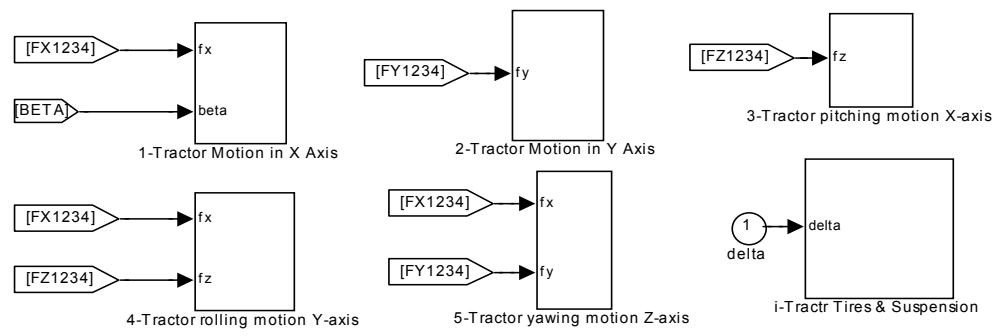

Fig.5. Tractor model

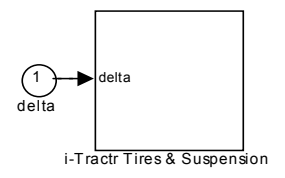




\subsection{Semi trailer model}

Semi trailer is simulated as a different mass driven by the tractor, so tractor velocities $(u, v, \omega, \varphi, \alpha)$ are transferred instantaneously to the semitrailer through the fifth wheel (hitch point), accordingly a mutual interaction the fifth wheel forces $\left(\mathrm{F}_{\mathrm{Hx}}, \mathrm{F}_{\mathrm{Hy}}, \mathrm{F}_{\mathrm{Hz}}\right)$ are generated and applied to both.

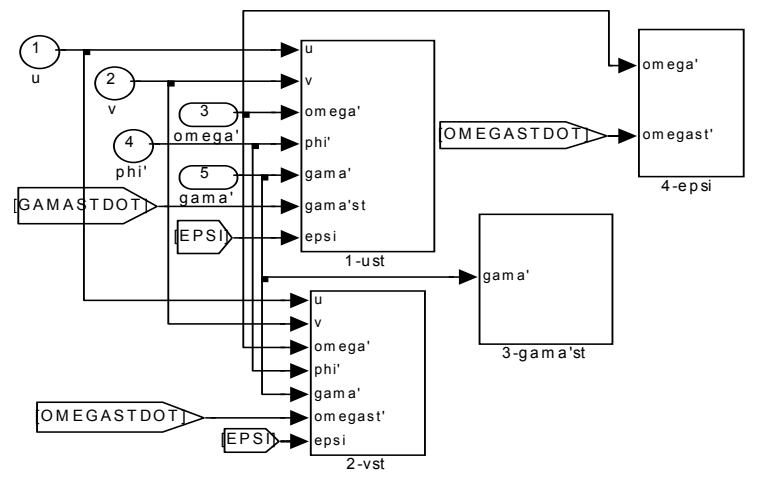

Fig.6. Semi trailer model

The outputs of the semitrailer model are: semitrailer longitudinal, lateral yawing, rolling, pitching velocity, fifth wheel longitudinal, lateral, and normal forces as shown in figure 6.

\subsection{Axle and suspension model}

On all road vehicles the chassis movement is actively guided by steering, throttling, braking, and possibly suspension actuations, which all ultimately result in forces in the tire road interaction. An axle and suspension model was created to achieve this; there are two axle types, a steerable single tire axle to simulate the tractor front axle, and non-steerable dual tire axle to simulate the tractor rear axle, and semitrailer axles as shown in figures 7 . The axle model consists of 2 suspensions as shown in figure 8 with four tires according to the tractor semitrailer configuration.

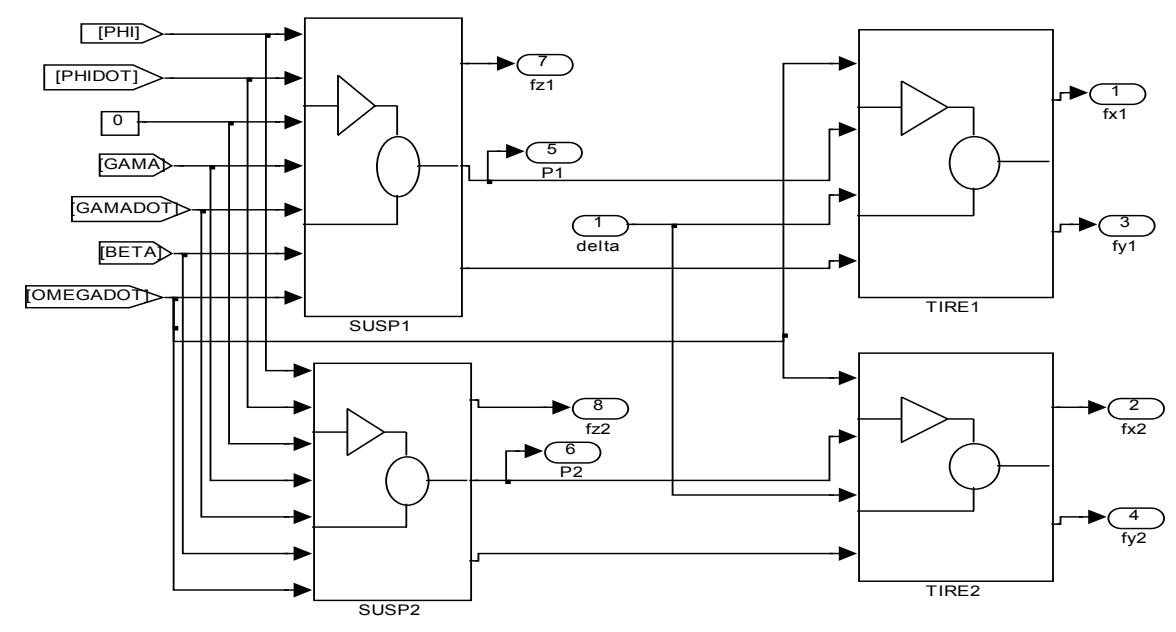

Fig.7. Dual tire axle model 


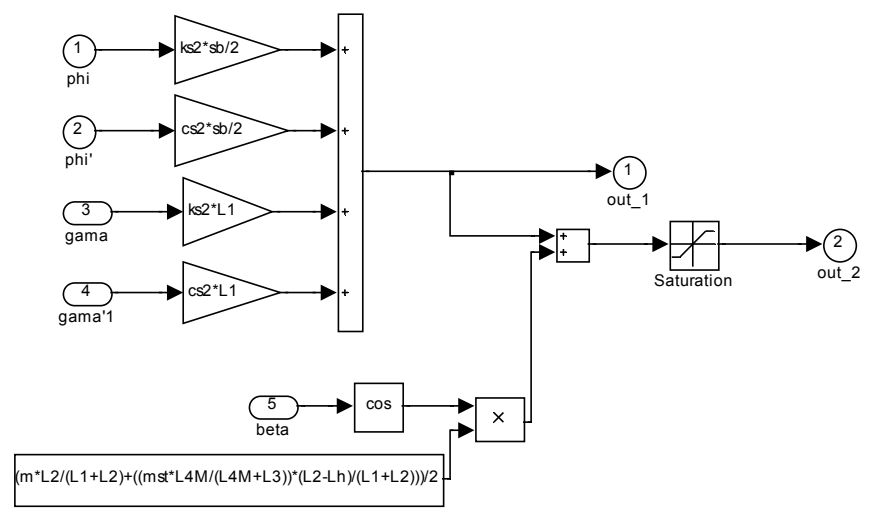

\subsection{Tire model}

Fig.8. Suspension model

The tires performance has the major influence on the dynamic behavior of a vehicle. Obviously, accurate tire models are necessary for analyzing and simulating vehicle motion in real driving conditions. With new active chassis control systems that are based on unilateral braking it is increasingly important to describe the effects of combined braking and cornering correctly, also near and beyond the tire road friction limits. A ready made Matlab file called STI developed by System Technology Corporation was adopted to calculate the tire forces. Tire normal load, slip ratio, \& slip angle are the inputs to the model, then through a series of algebraic and empirical equations based on experiments are used to produce longitudinal and lateral forces.

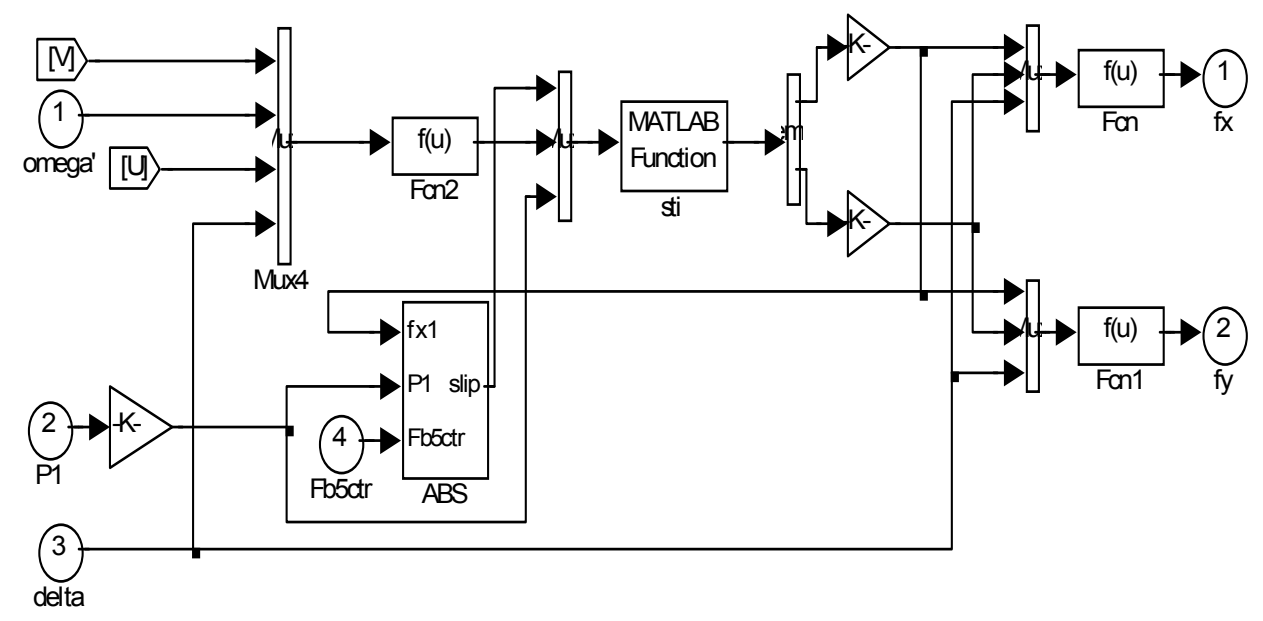

Fig.9. Tire model 
The input normal load was multiplied by a scale factor and the output longitudinal and lateral forces were multiplied by anther scale factor, these scales were chosen to match STI results with previous work introduced by [M. El-Gindy and S. Chae The Pennsylvania State University March, 2001, dry road condition] shown in Figure10 to get the STI results to be suitable for a tractor semitrailer combination (Heavy vehicles).
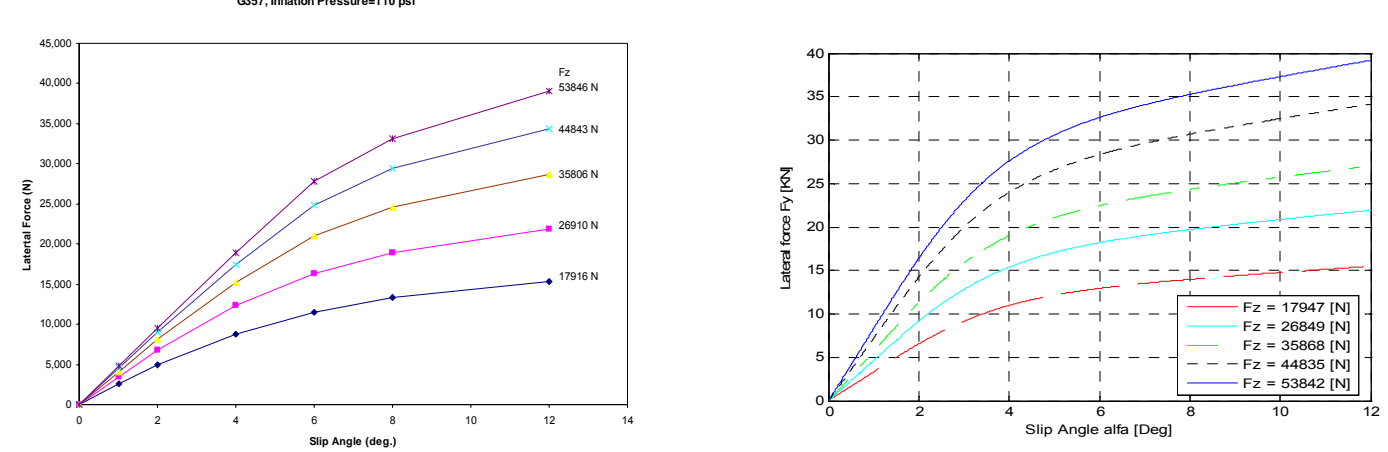

Fig.10. Tire characteristics [M. El-Gin dy and S. Chae The Pennsylvania State University March, 2001] [Modified STI]

\subsection{Brake model}

A ready made anti-locking braking system (ABS) model from Simulink library was utilized to simulate the braking performance for the combination. This model is activated through applying braking force for each wheel to maintain a desired slip (0.2) avoiding locking of the tire as shown in figure 11.

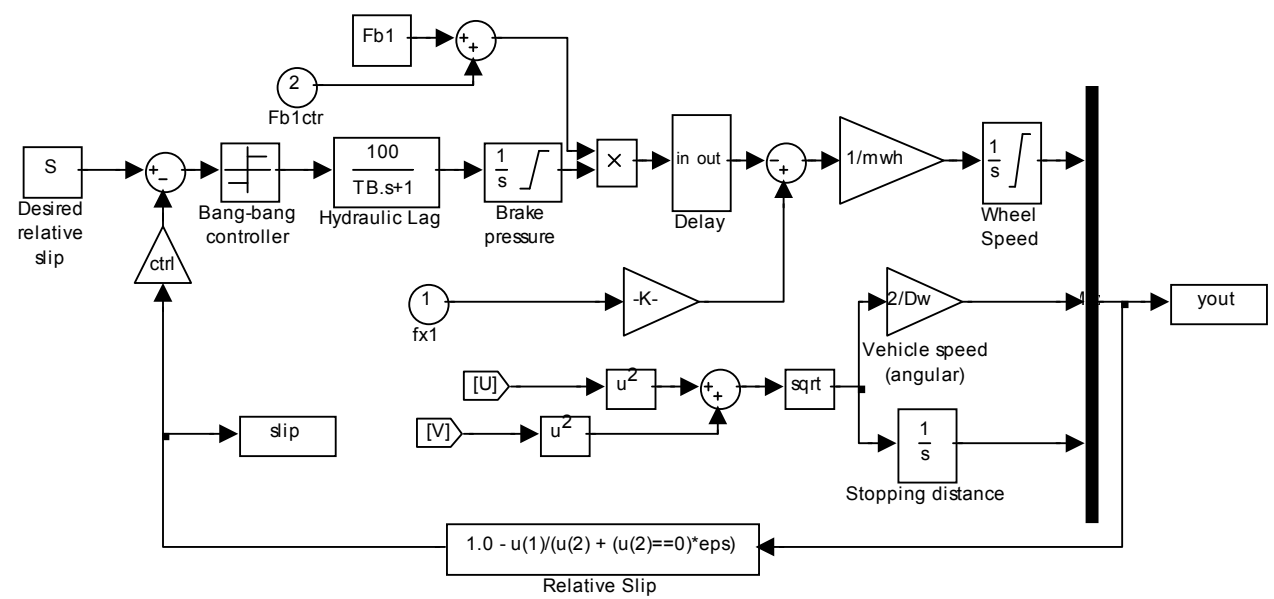

Fig.11. Brake system model 


\subsection{Validation of the simulation program}

Simulation results are compared with those achieved through published papers to verify the model.Validation of the simulation Program is done by applying the vehicle parameters and conditions introduced by Tetsuya Kaneko [5] and comparing the results as shown in figure 12,13 respectively .

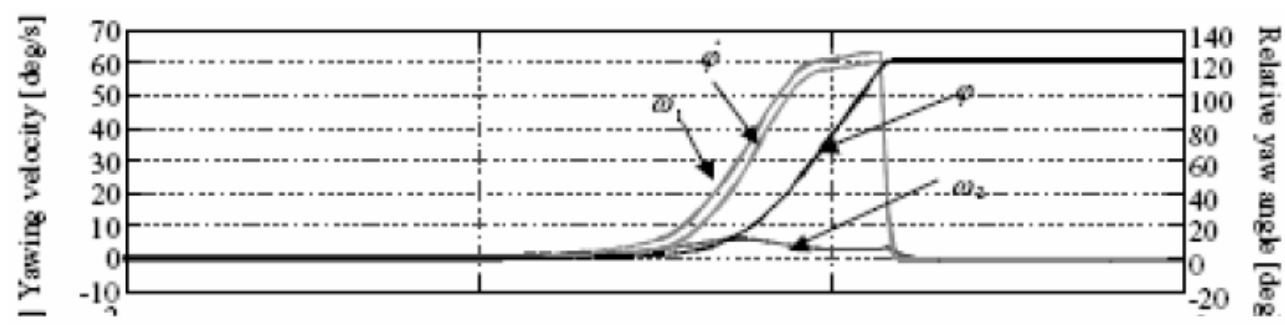

[Tetsuya Kaneko]

Fig.12. Simulation result by Testuya Kaneko[5]

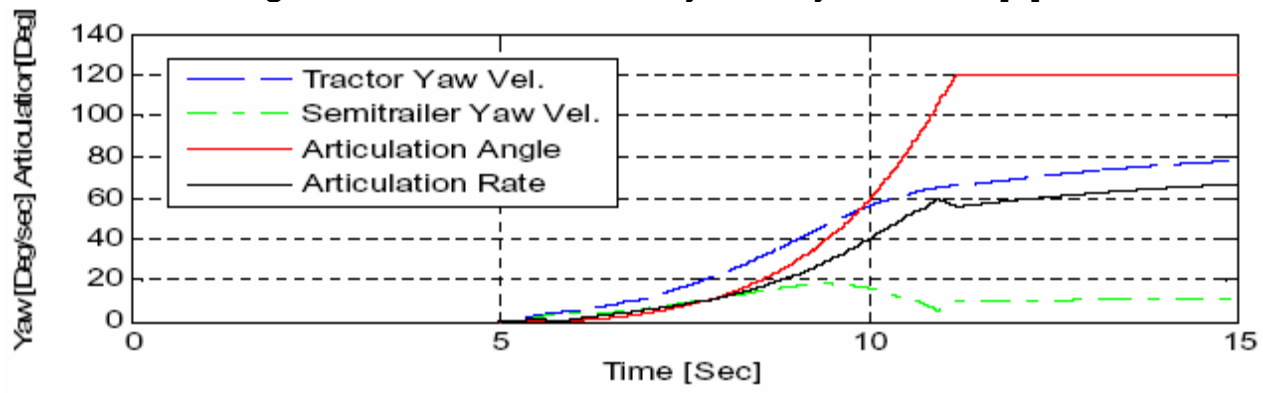

Introduced Simulation Program Results

Fig.13. Simulation result from the established program

\subsection{Jackknifing problem during evasive high speed maneuver}

The 2 axel tractor combined with 3 axle semitrailer is simulated to move straight forward at different initial speeds $\left(u_{0}=70,80,90\right.$, and $\left.110 \mathrm{~km} / \mathrm{h}\right)$ for $2 \mathrm{sec}$. and then the driver faces an obstacle so he had to make an evasive lane change maneuver with front steering angle pattern as shown in Figure 1 The driver response was taken into consideration (15, and $30 \mathrm{deg} / \mathrm{Sec}$ ), under different driving conditions, with or without braking, on dry or wet road, with empty or fully loaded semitrailer.

\subsection{Determination of stable performance limit}

To determine the stable performance limit several simulations were made using the defined Simulink Matlab program in the previous chapter for a 7 [Ton] 2-axle tractor combined with 44 [Ton] (fully loaded) 3-axle semitrailer, at different initial speed $\left(u_{0}=\right.$ $70,80,90,100,110 \mathrm{~km} / \mathrm{hr}$ ), dry road condition ( $\mu=0.85)$, applying an evasive maneuver steering input shown in Figure 1, without braking, Figure 14 shows the combination path at different initial speeds[yaw plane]. 


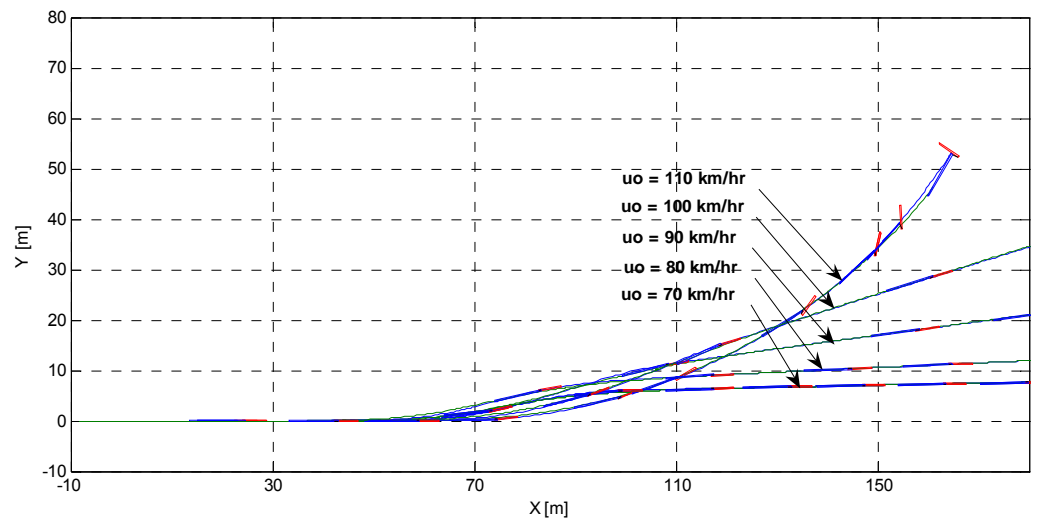

Fig.14. Lane change maneuver with different initial longitudinal velocities $\left(u_{0}\right)$ [yaw plane]

Inspection of the Figure 14 shows that:

- At $u_{0}=70 \mathrm{~km} / \mathrm{hr}$ : the combination achieved a stable path.

- At $\mathrm{u}_{0}=80$ to $100 \mathrm{~km} / \mathrm{hr}$ : a drift out from the stable path takes place.

- At $\mathrm{u}_{0}=110 \mathrm{~km} / \mathrm{hr}$ : jackknifing takes place.

\subsection{Simulation results of the jackknifing case $u_{0}=110 \mathrm{~km} / \mathrm{hr}$}

Simulation was made using the Simulink Matlab program for a 7 Ton 2-axle tractor combined with 44 Ton (fully loaded) 3-axle semitrailer, at initial speed $u_{0}=110 \mathrm{~km} / \mathrm{hr}$, on dry road $(\mu=0.85)$, applying an evasive maneuver steering input shown in Figure 1, without braking Figure 15 shows the motion of the tractor semitrailer in the yaw plane plane, tractor is represented by the small rectangle, while semitrailer is represented by the big rectangle as shown in figure 15.

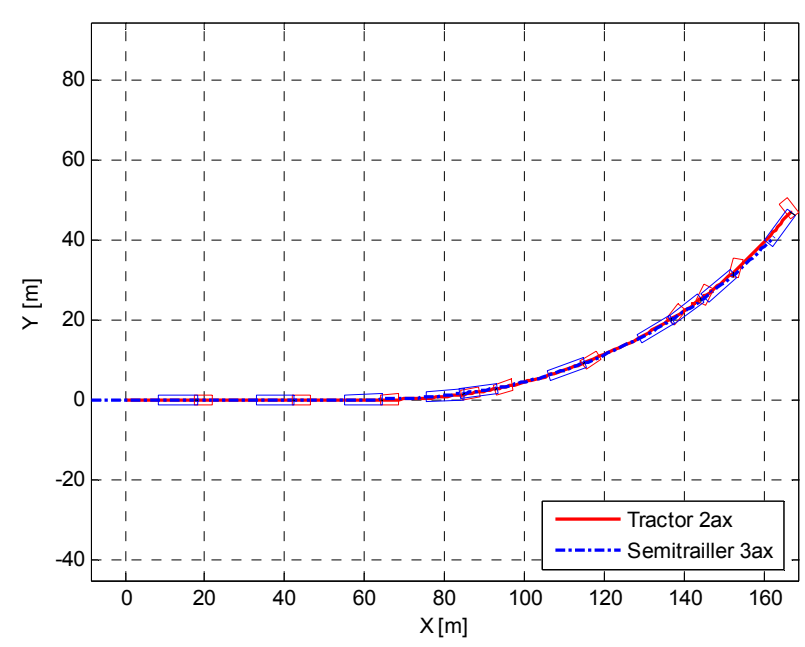

Fig.15. Tractor Semi trailer path [yaw plane]

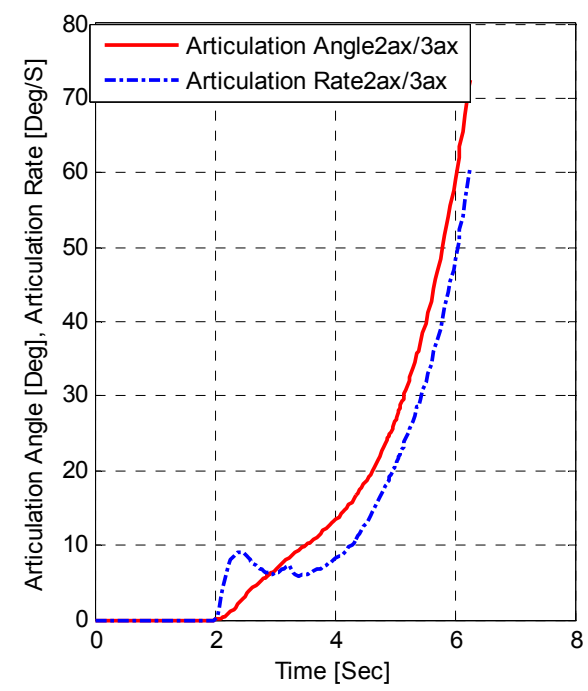

Fig.16. Articulation angle, and rate of Tractor Semi trailer[yaw difference]

The articulation angle (yaw angle difference between the tractor and the semitrailer), and the articulation rate drastically increase resulting in a tractor jackknifing as shown in Figure 16. the tractor yaw rate increases rapidly to reach $95 \mathrm{Deg} / \mathrm{sec}$. while the 
semitrailer yaw rate was $20 \mathrm{Deg} / \mathrm{sec}$. resulting in a high articulation rate as shown in Figure 17,18.

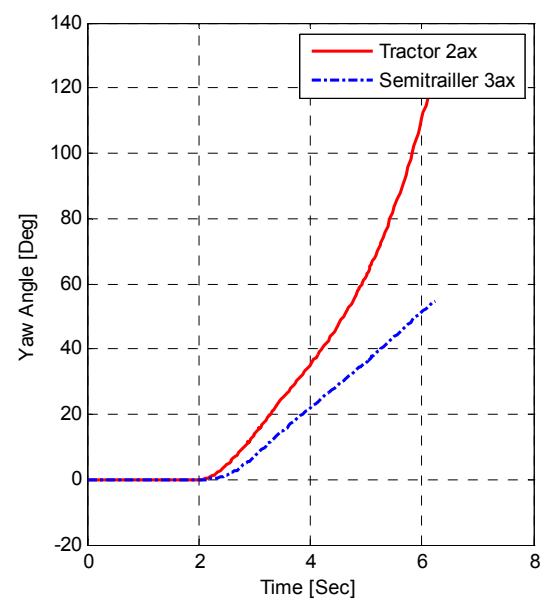

Fig.17. Tractor and Semitrailer

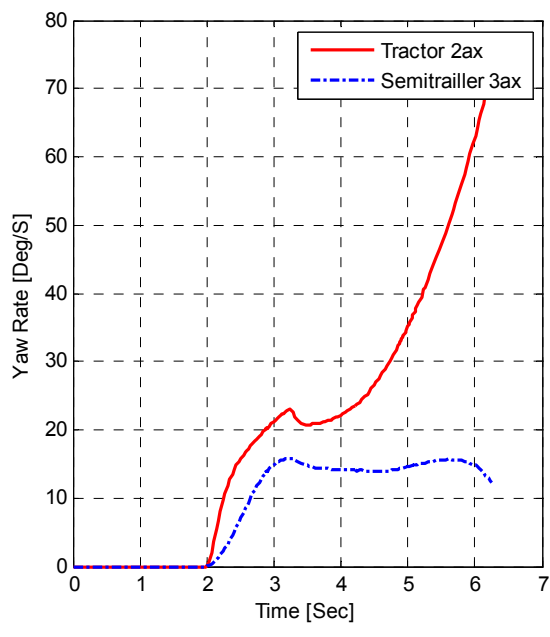

Fig.18. Tractor \& Semitrailer Yaw Rate

The tractor pitch rate oscillates resulting in an increase to the pitch angle to the value of 0.25 Deg. while the semi trailer pitch rate and angle don't change significantly as shown in figure 19. The semi trailer roll angle rate and oscillate with an amplitude greater than the tractor due to difference in moment of inertia until the $7^{\text {th }} \mathrm{sec}$. then the tractor jackknife to the semitrailer as shown in figure 19, 20.

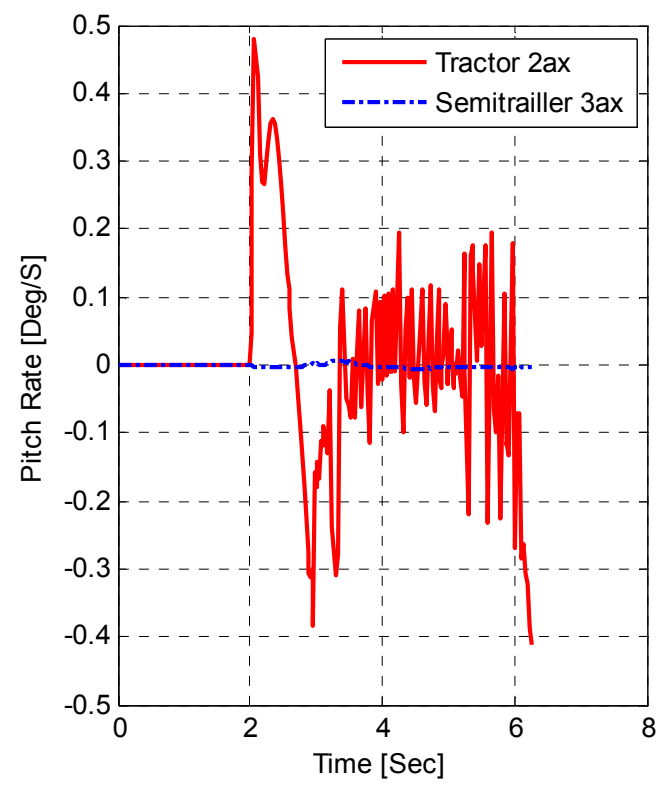

Fig.19. Tractor and Semitrailer Roll Angle

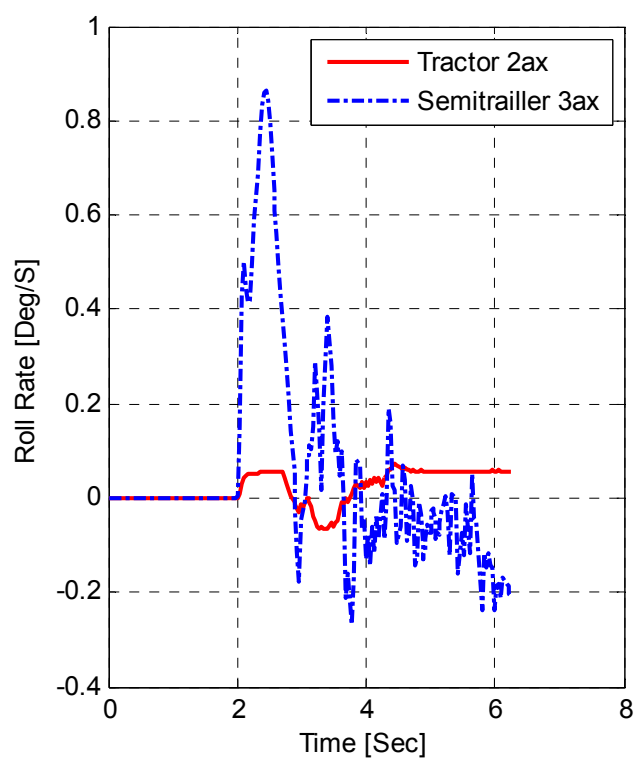

Fig.20. Tractor and Semitrailer Roll Rate 
Inspection of Figure 21 and Figure 22 shows that tractor longitudinal speed decreases rapidly till zero while its lateral speed increases in the negative direction. On the other hand, the semitrailer almost maintains its resultant velocity direction.

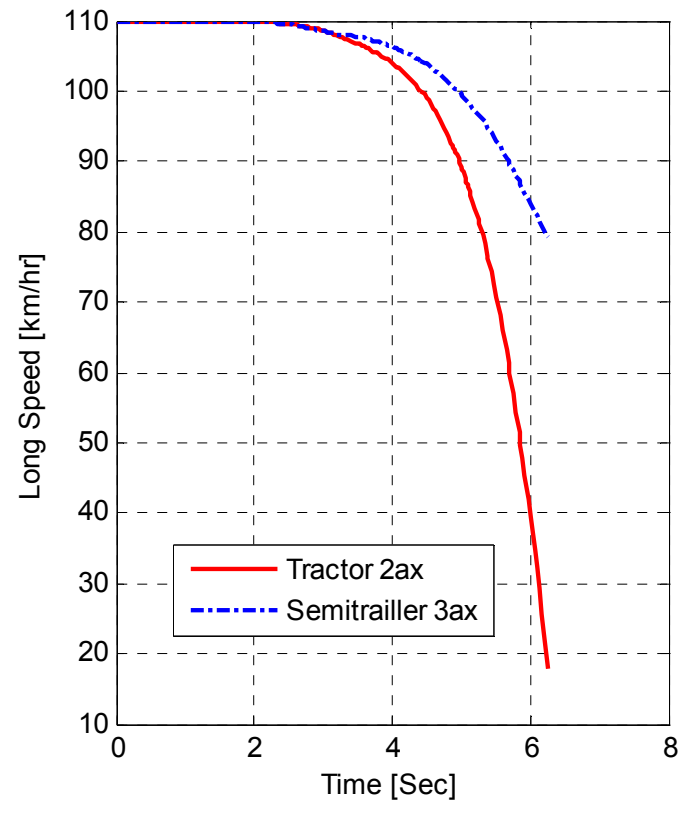

Fig.21. Tractor and Semitrailer Longitudinal speed

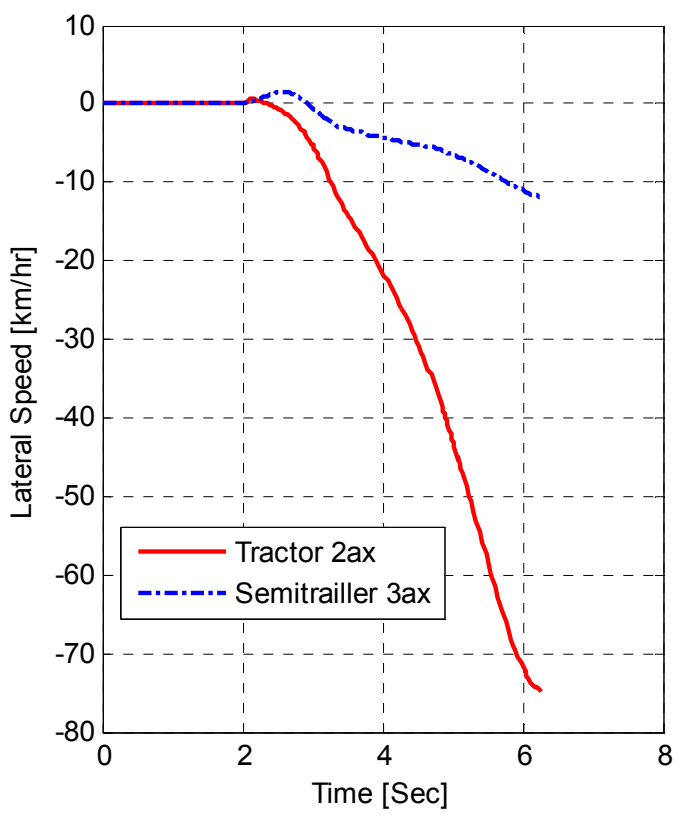

Fig.22. Tractor and Semitrailer Lateral Speed 


\subsection{Jackknifing analysis}

From the previous simulation results with initial speed $u_{0}=70 \mathrm{~km} / \mathrm{hr}$, and $\mathrm{u}_{0}=110 \mathrm{~km} / \mathrm{hr}$, the former will be considered as the ideal successful maneuver, and the later will be analyzed to find out a solution for the combination to obey the former path. The jackknifing takes place when the articulation rate increases rapidly during the evasive high speed maneuver, this happens as a result of a difference in the longitudinal speed between the tractor and the semitrailer where the later pushes the tractor and the semitrailer is at an angle to it, resulting in high lateral forces on the tractor tires greater than the instantaneous available tire road interaction adhesion limit as shown in Figure 23.
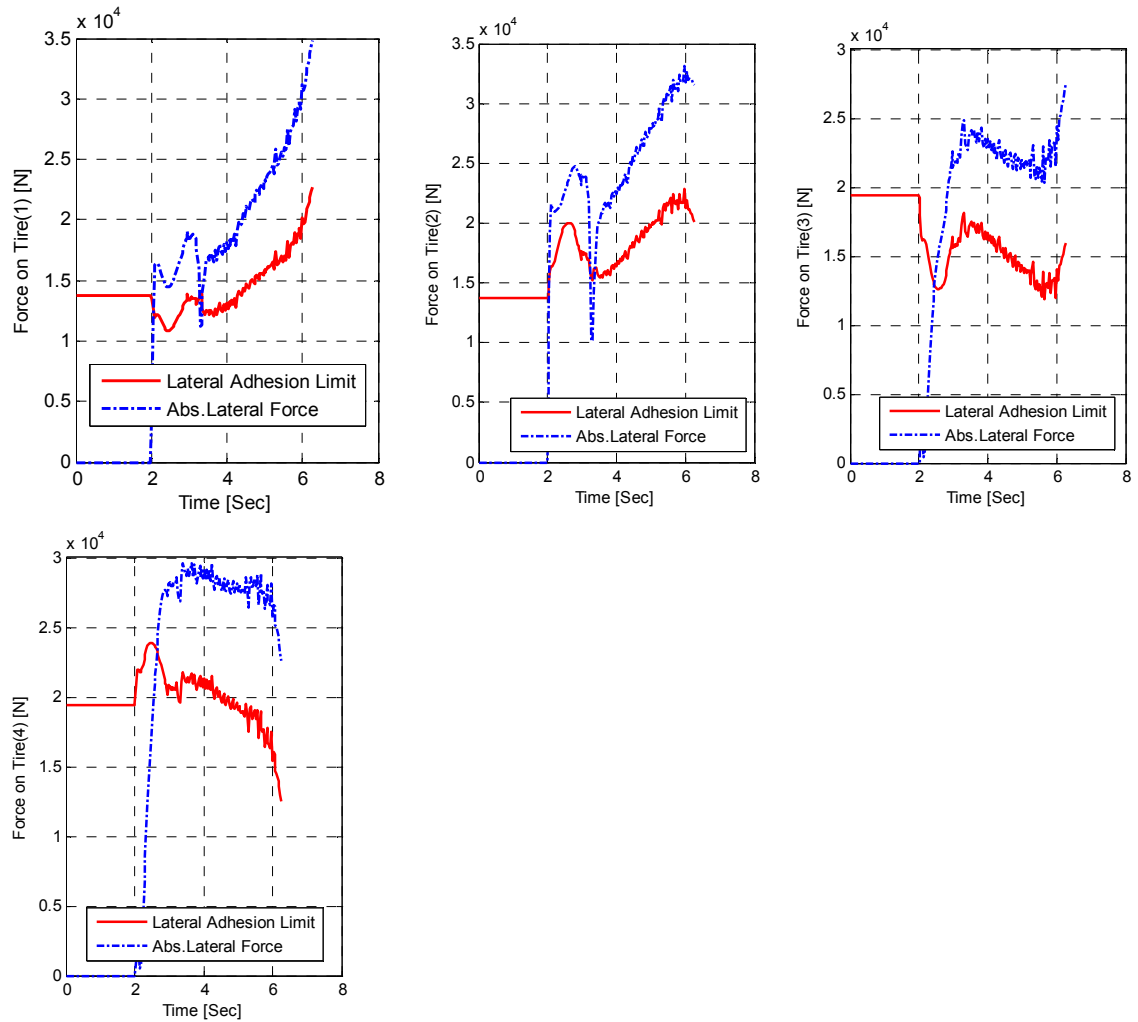

Fig.23. Tractor Absolute Lateral Force, lateral Adhesion Limit: u0=110km/hr

\subsection{Elimination of jackknifing during high speed evasive maneuver}

From the previous analysis of the jackknifing problem it is concluded that to avoid pushing of the tractor by the semitrailer and consequently the arise of undesired lateral forces on the rear tractor tires, the semitrailer instantaneous longitudinal velocity must be reduced to a value approximately equal to that of the tractor during the evasive maneuver at high speed.

\subsection{Proposed semitrailer differential brake technique (SDBT)}

For a tractor semitrailer combination equipped with an antilock braking system The primary aim of the model is simulation of handling different scenarios with active 
articulation rate control (between tractor \& semitrailer), using differential braking applied on semitrailer tires (only) that have enough surplus in tire road interaction as shown in figure 24.

The proposed control strategy (SDBT) improve the behavior of both the tractor and semitrailer equipped with standard anti lock braking system (ABS) simultaneously, if the surplus in the tire road adhesion limit deceases, the potential for improvement in the directional behavior is reduced. Nevertheless, even in wet road surfaces, (SDBT) can improve the dynamic stability during severe maneuvers at $110 \mathrm{Km} / \mathrm{hr}$ forward speed under dry/wet road conditions at different driver responses. The applications of (SDBT) has good influence not only on the in-plane motion of the tractor semitrailer combination but also on the roll motion of both the tractor and semitrailer. When applying this control strategy, semitrailer differential brake technique (SDBT), the forward speed of the combination decrease slightly $(<5 \mathrm{Km} / \mathrm{hr})$. The articulation rate threshold that the (SDBT) should be activated is $0.02 \mathrm{rad} / \mathrm{sec}$ (The Yaw rate difference between the tractor and semitrailer). Inspection of figure 23,and figure 36 show that the lateral forces on rear tractor tires generated during the maneuver at high speed exceeded the available lateral adhesion limit resulting in tractor jackknifing. On the other hand by monitoring the articulation rate, till reaching a critical value the (SDBT) starts the application of the brake force $(0.002$ times the normal load) on the semitrailer tires that have suitable adhesion limit resulting in lower lateral forces on tractor tires lower than the adhesion limit that can withstand resulting in stable performance of the combination without jackknifing

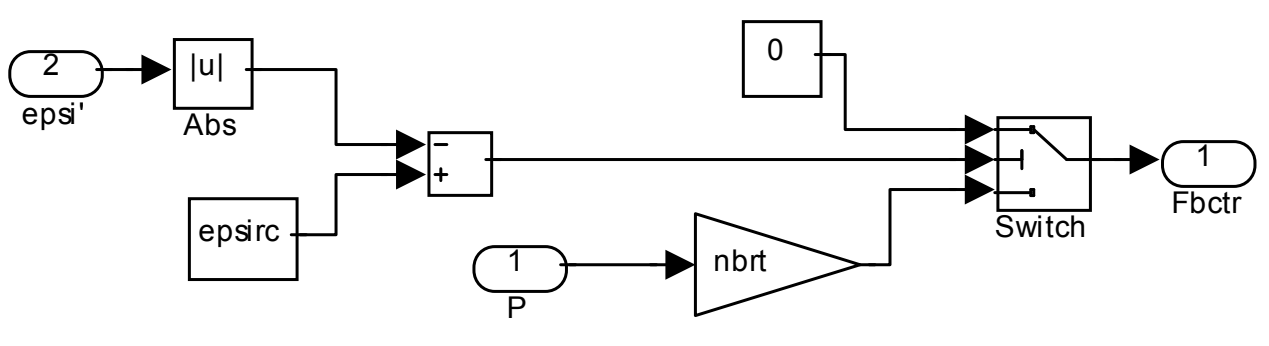

Fig.24. Scheme of the SDBT control system

\subsection{Computer simulation using the proposed semitrailer differential brake technique (SDBT)}

Computer simulations are carried out to verify the effectiveness of the control system designed in this study. The simulations are conducted under the conditions that the road friction coefficients are 0.85 . The controller is designed at the condition that the vehicle speed is $110 \mathrm{~km} / \mathrm{hr}$ 


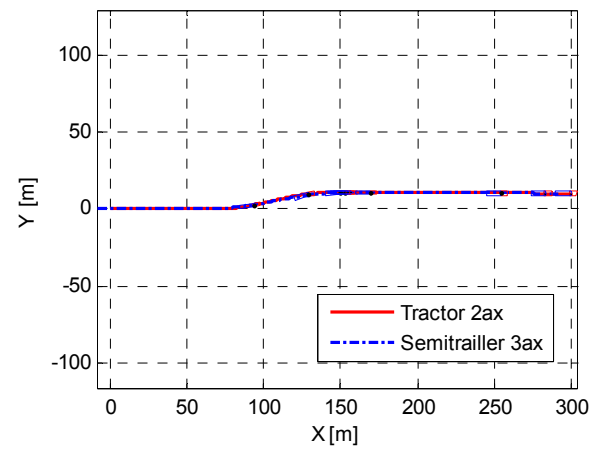

Fig.25. Tractor Semi trailer path [Yaw plane] using SDBT

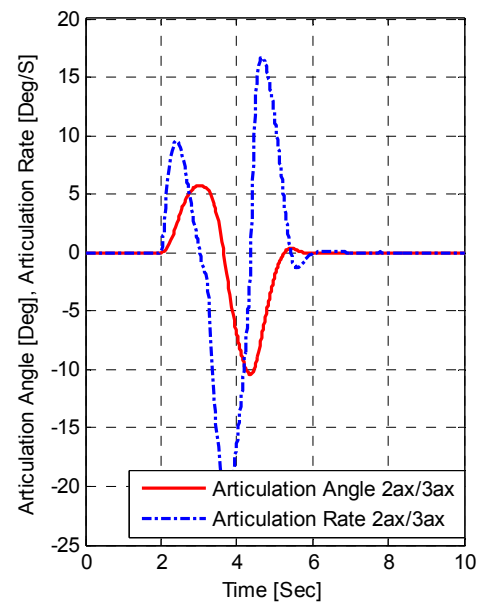

Fig.26. Articulation angle, and rate of Tractor Semi trailer using SDBT

The articulation angle (yaw angle difference between the tractor and the semitrailer), and the articulation rate( Figure 26) decrease to a value of -10 [deg]and $-23[\mathrm{deg} / \mathrm{s}$ ] respectively resulting in successful path as shown in Figure 25 during an evasive lane change maneuver, the tractor yaw angle and rate decreases to a value of 16 [deg] and -15 [deg/s] respectively while the semitrailer yaw angle and rate didn't exceed 17[deg] and $-17[\mathrm{deg} / \mathrm{s}]$ respectively as shown in Figure 27,28. Tractor and semitrailer pitch and roll rate are shown in figure 29 and 30 respectively.

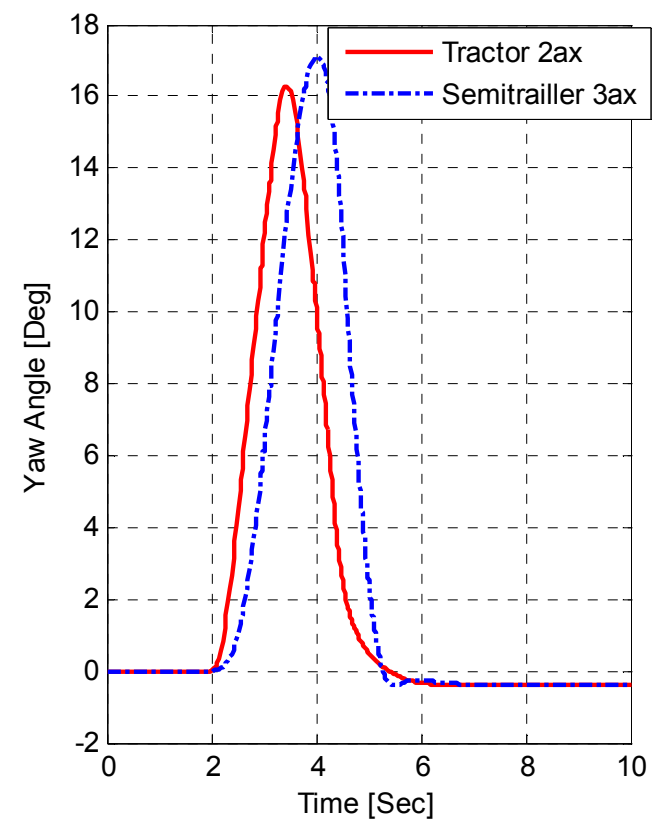

Fig.27. Tractor and Semitrailer Yaw Angle using SDBT

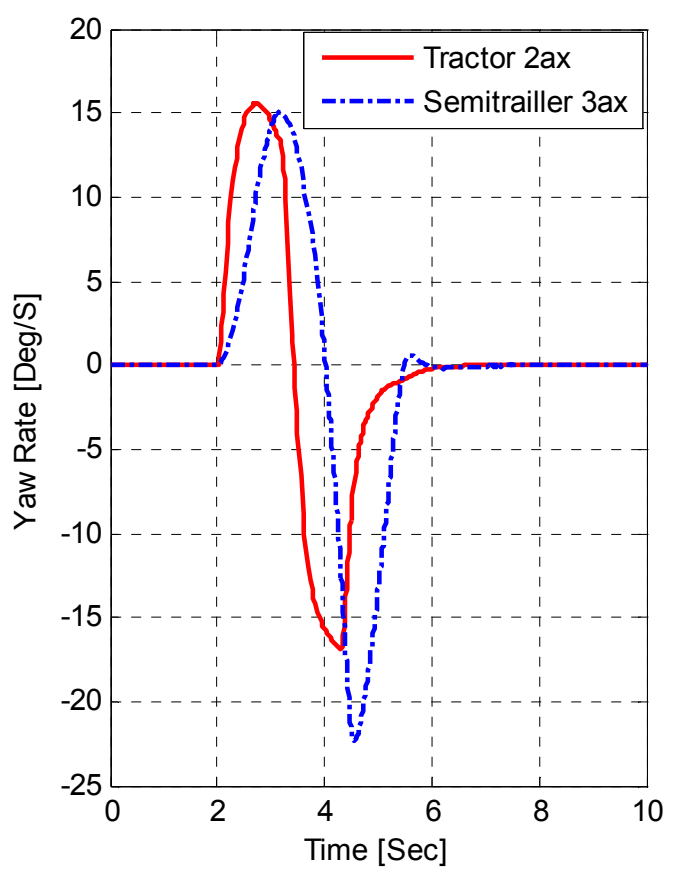

Fig.28. Tractor \& Semitrailer Yaw Rate using SDBT 


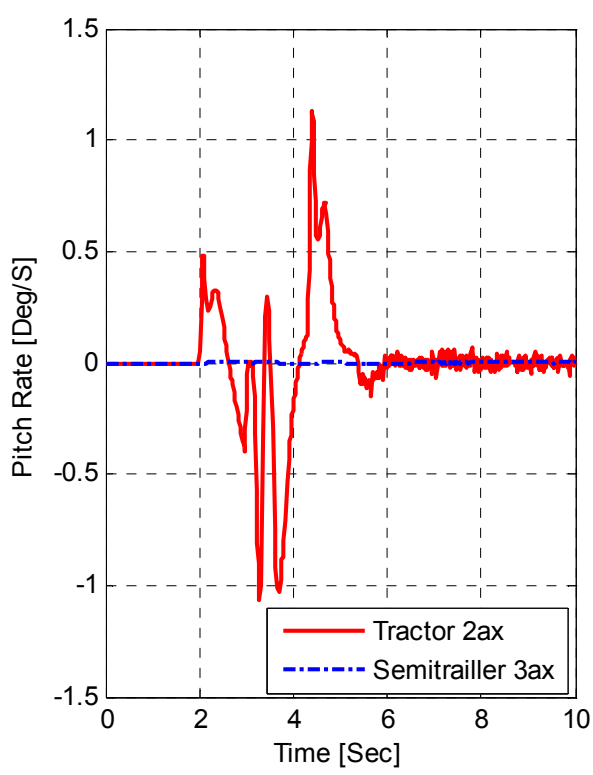

Fig.29. Tractor and Semitrailer Pitch Rate

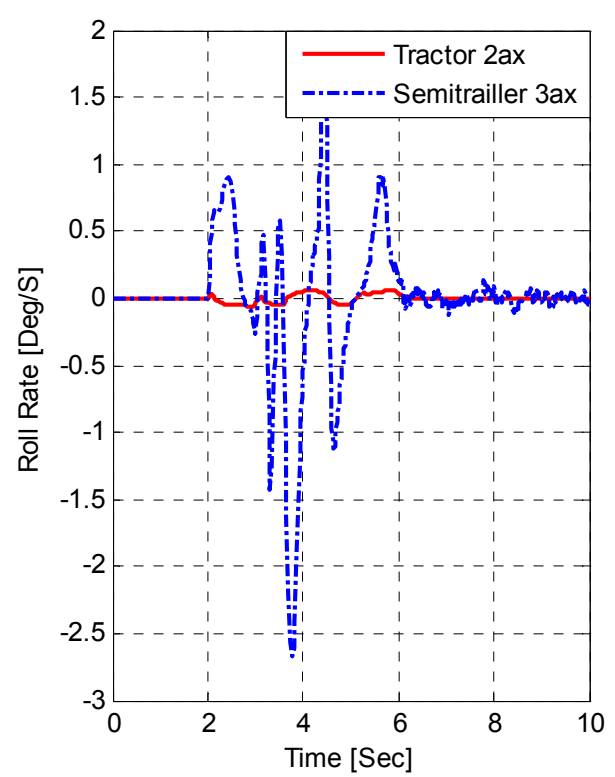

Fig.30. Tractor and Semitrailer Roll Rate

Inspection of Figure 31 and Figure 32 shows that semitrailer longitudinal speed decreases slightly to a value approximately $106.5[\mathrm{~km} / \mathrm{hr}]$ while its lateral speed increases slightly to a value approximately $-15[\mathrm{~km} / \mathrm{hr}]$ in the negative direction. On the other hand, the tractor longitudinal speed decreases slightly to a value approximately 107.75 [km/hr] while its lateral speed increases slightly to a value approximately $-6[\mathrm{~km} / \mathrm{hr}]$ in the negative direction resulting in successful path as shown in Figure 25 during an evasive lane change maneuver. to avoid an obstacle at combination longitudinal speed $110[\mathrm{~km} / \mathrm{hr}]$. the dynamic tire normal loads for the tractor semitrailer are shown in figure 33and figure 34 .Figure 35 shows fifth wheel forces

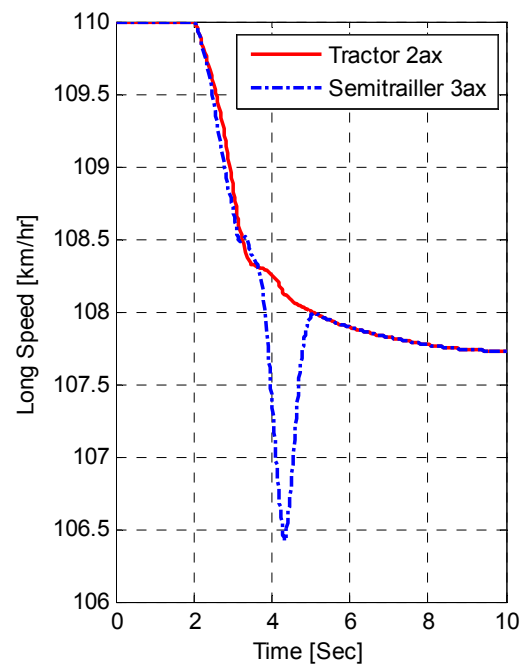

Fig.31. Tractor and Semitrailer Longitudinal speed using SDBT

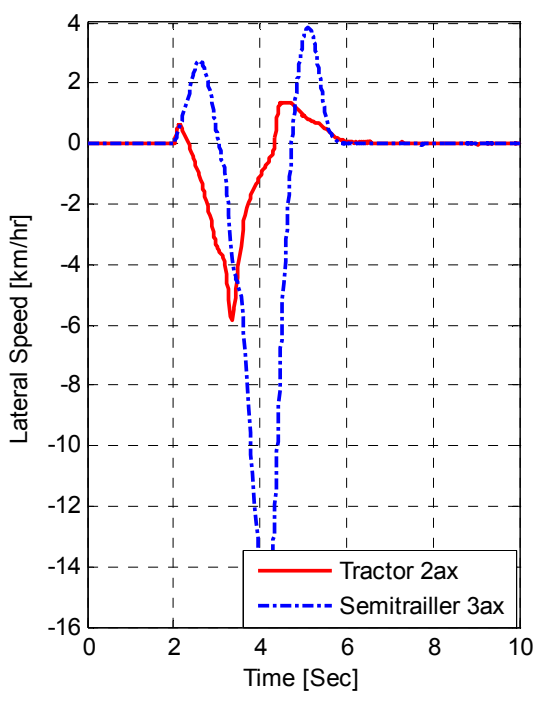

Fig.32. Tractor and Semitrailer Lateral Speed using SDBT 

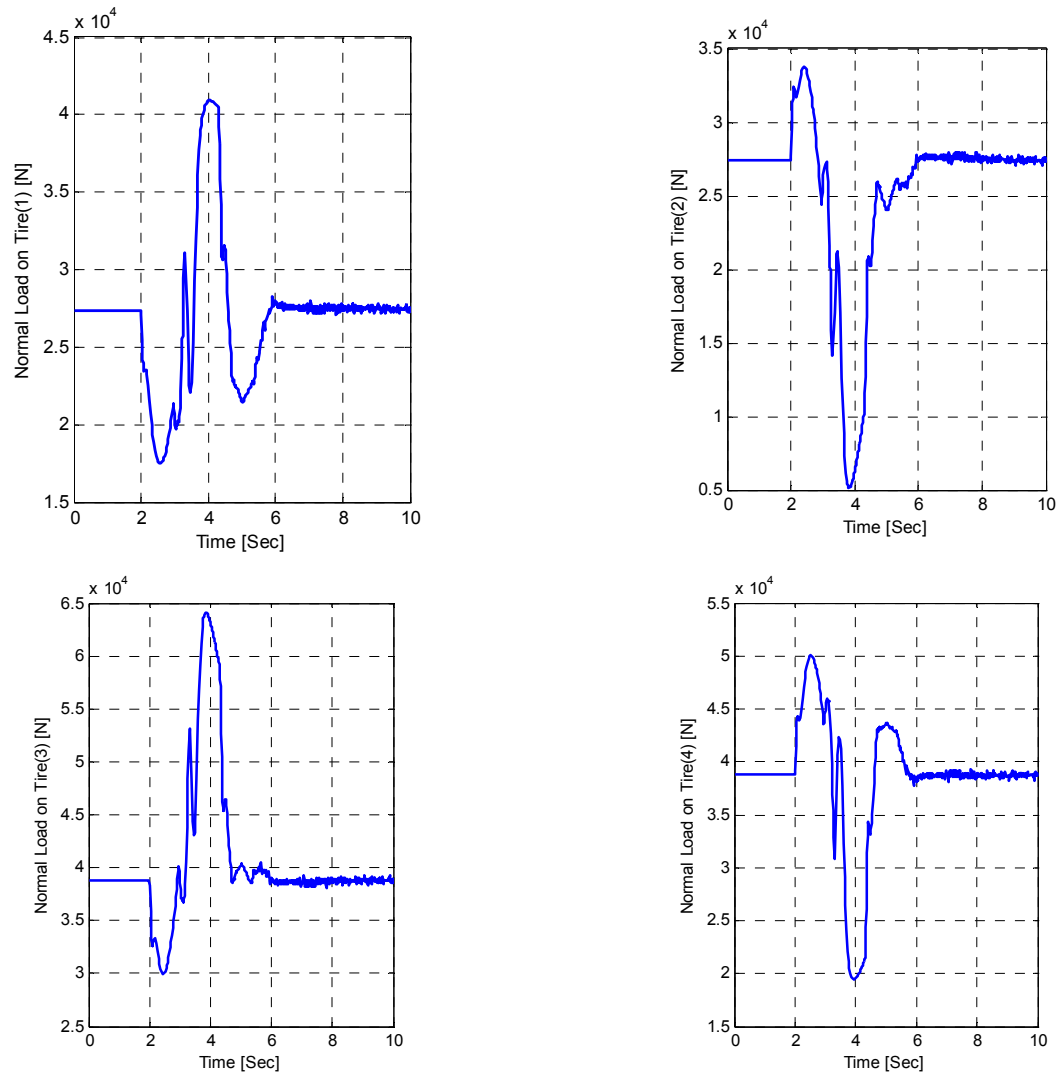

Fig.33. Normal load on tractor tires $1,2,3,3^{\prime}, 4,4[\mathrm{~N}]$ using SDBT
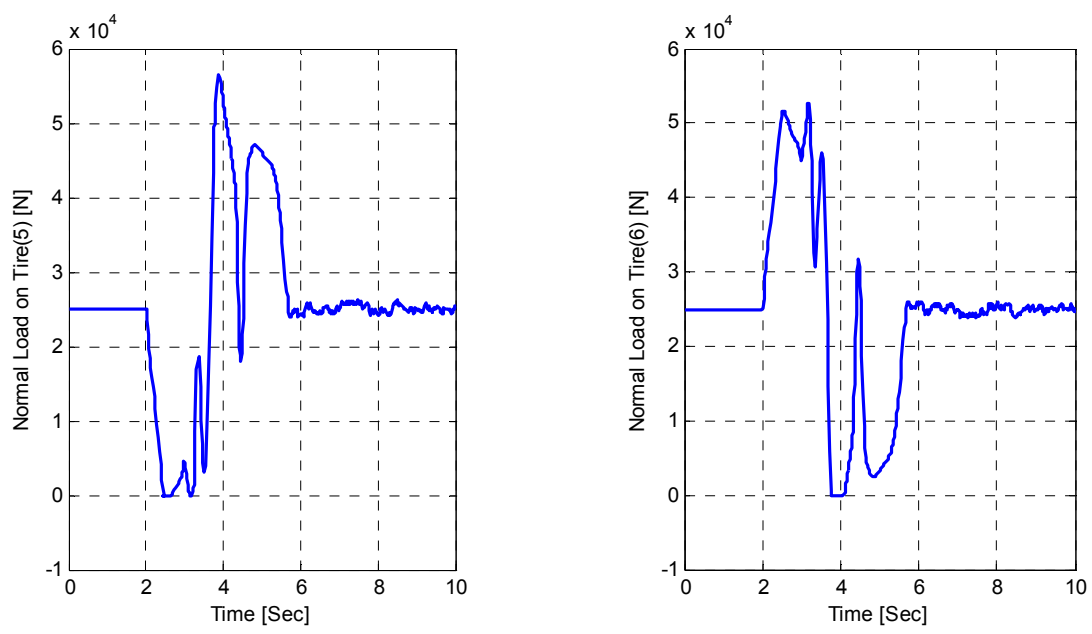

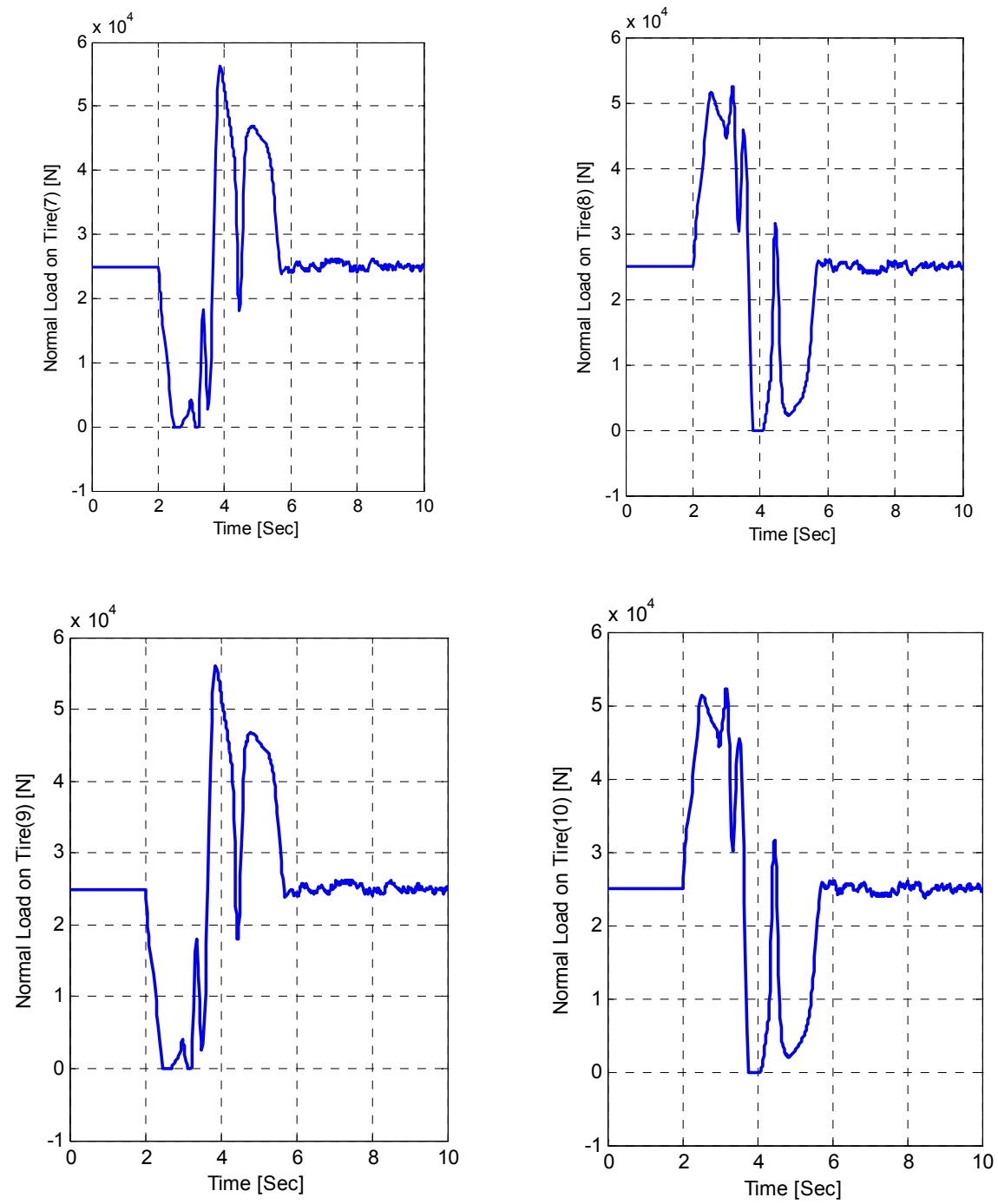

Fig.34. Normal load on semi-trailer tires $5,5^{\prime}, 6,6^{\prime}, 7,7^{\prime}, 8,8^{\prime}, 9,9^{\prime}, 10,10^{\prime}$ [N]
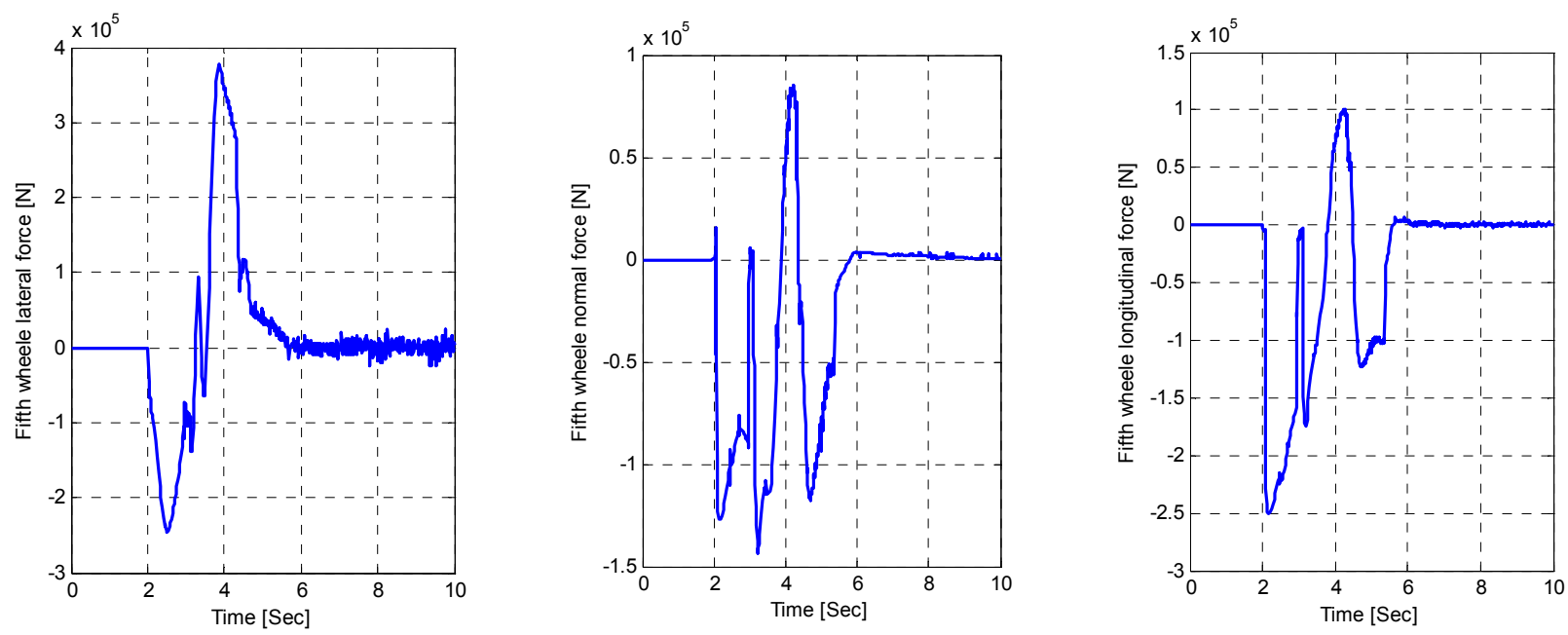

Fig.35. Fifth-wheel forces using SDBT 
Inspection of figure 36 shows lower lateral forces on tractor tires lower than the lateral adhesion limit that can withstand resulting in stable performance of the combination without jackknifing
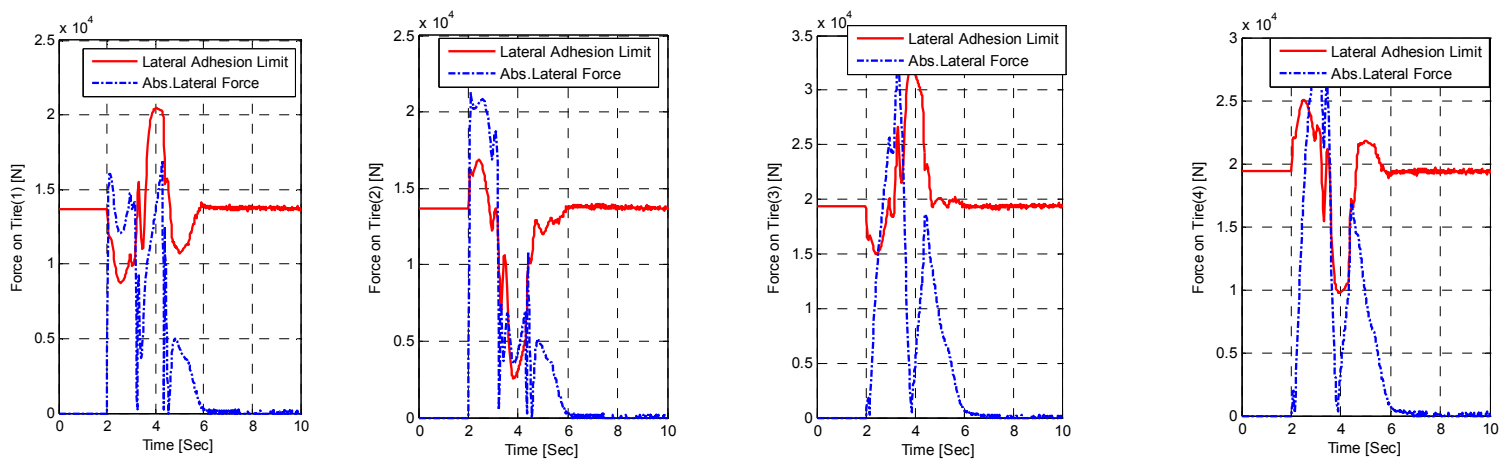

Fig.36. Absolute Lateral Force, lateral Adhesion Limit:u0=110km $/ \mathrm{hr}$,

$$
\mu=0.85, \dot{\delta}=30 \mathrm{Deg} / \mathrm{sec} \text {, loaded, using SDBT }
$$

\section{CONCLUSIONS}

1. A 2 axle tractor combined with 3 axle semitrailer Matlab Simulink model was established to study the dynamic stability under different driving conditions (brake sequence, driver input, steering response, road type \& grade, loading condition, and the combination dimensions).

2. The results of the model are validated by applying the vehicle parameters and conditions introduced by [Tetsuya Kaneko] [5] and comparing the results.

3. The dynamic stability of the combination during sever high speed[110kmlhr] maneuver has been improved by contributing additional control strategy logic to the standard antilock braking system through the articulation rate monitoring[0.02rad/s]using semitrailer differential braking technique (SDBT) on semi trailer tires[0.002times the normal load ]

4. The new proposed control logic strategy will make the semitrailers act as smart equipment regardless of the driver response and tractor type since tractors and semi trailers are built by different manufacturers.

\section{REFERENCES}

[1] Zeyada Y.M.," Integrated Active Systems for Emergency Maneuvers in Automobiles." PhD thesis, Cairo university ,Faculty of Engineering,1999.

[2] Kusters L.J.J., " Increasing Roll - Over Safety of Commercial Vehicles by Application of Electronic Systems." "Smart Vehicles."Pauwelussen J.P.and Pacejka H.B.ed.,Swets and Zeitlinger,1995,pp.362-377.

[3] Dunwoody A.B.,"Active Roll Control of a Semi-Trailer." SAE Transactions, SAE 933045 (Nov), 1993.

[4] R.D.Ervin, "The Influence of Size and Weight Variables on Roll Stability of Heavy Duty Trucks," Tech. Rep. 831163, Society of Automotive Engineers, 1983.

[5] Tetusya Kaneko, Ichiro Kageyama " A Study on the braking stability of articulated heavy vehicles " JSAE Review 24(2003) 157 - 164

[6] J.Y. Wong. Theory of Ground Vehicles. Number ISBN 0-471-35461-9. John Wiley\& Sons, Inc., 2001.

[7] Rakheja,s. and Piche,A., "Development of Directional Stability Criteria for An Early Warning Safety Device," SAE Paper No.902265,1990. 
[8] Winkler,C. et al. "Cooperative Agreement To Foster The Deployment of A Heavy Vehicle Intelligent dynamic Stability Enhancement System, "University of Michigan Transportation research institute, interim report ,NHTSA-U.S.DOT Contract No.dtnh22-95-h-07002, January 1998.

[9] Naleecz, A. G. et al., "An investigation into dynamic measure of vehicle rollover Propensity," SAE paper No.930831, 1993.

[10] Allen,R. W., Rosenthal, T. J. and Szostak, H. T.," Analytical Modeling of Driver Response in Crash Avoidance Maneuvering, Volume I; technical background," DOTHS-807-270,April 1988.

[11] D.J.M. Sampson and D.Cebon." An Investigation of Roll Control System Design For Articulated Heavy Vehicles." Cambridge University Engineering Department. Paper AVEC 1998.

[12] E.Bakker, H.B. Pacejka, and L. Lidner."A New Tire Model with An Application in Vehicle Dynamic Studies.SAE890087, 1989.

[13] H.B. Pacejka." Modeling of The Pneumatic Tire and Its Impact on Vehicle Dynamic Behavior." .Delft, Delft, 1988.

[14] M.El-gindy,L.Palkovics ." Design of an active unilateral brake control system for five-axle tractor - semitariler based on sensitivity analysis." $6{ }^{\text {th }}$ AMME confer., May, 1994.

[15] M. El-Gendy and J.Y. Wong "Steering Response of Articulated Vehicles in Steady state Turns," Society of Automotive Engineers, Paper 852335,1985.

[16] EL-Gindy, M. and Preston Thomas, J. "Static Rollover Threshold of Heavy Trucks", Ground Transportation Technology Program, National Research Council Canada, 1992.

[17] Winkler, C. B., Karamihas, S. M., and Board, S. E. "Roll Stability Performance of Heavy Vehicle Suspensions", University of Michigan Transportation Research Institute, SAE Paper No. 922426, March 1992.

[18] Leucht, P. M. "The Directional Dynamics of the Commercial Tractor-semitrailer Vehicle During Braking", Society of Automotive Engineers, Paper 700371, 1970.

[19] EL-Gindy, M. "An Overview of Performance Measures for Heavy Commercial Vehicles in North America", Center for Surface Transportation Technology, National Research Council of Canada, 1995.

[20] Ervin, R. D. "Truck Parameters Measurement", Chapter 21. Mechanics of Heavy Trucks and Truck Combinations. Course notes, Engineering Conference. University of Michigan Transportation Research Institute. An Arbor, Michigan. July 1994.

[21] Antovn, R. J., et al. "Vehicle Dynamic Handling Computer Simulation - Model Development, Correlation, and Application Using ADAMS", SAE Paper No. 860574, 1986.

[22] EL-Gindy, M. and Preston Thomas, J. "Static Rollover Threshold of Heavy Trucks", Ground Transportation Technology Program, National Research Council Canada, 1992.

[23] Fancher, P. S. and Mathew, A. "Safety Implications of Trucks Designed to Weigh over 80000 Pounds", SAE Technical Paper No. 891632, 1989.

[24] Y.He.A.Khajepour, J.Mcphee , and X.Wang." Dynamic modeling and stability analysis of articulated frame steer vehicles." International journal of Heavy vehicles systems.

[25] José Eduardo D’Elboux, José Roberto Saraiva, Nicolas Basile Valtas, Time and Distance in Acceleration of Road Commercial Vehicles Hélio Aparecido Navarro DEMAC - UNESP Antônio Carlos Canale EESC - USP Mercedes-Benz do Brasil S.A. 